\title{
Os universos cénicos de Gonçalo Amorim
}

\section{Maria Helena Serôdio}
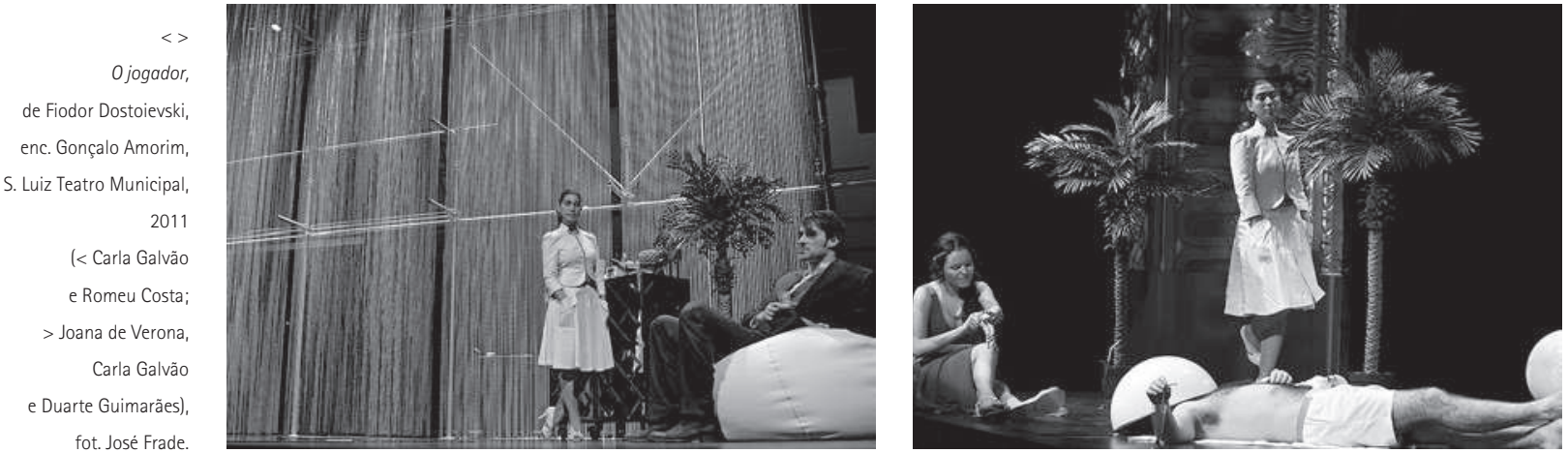

Já passaram quantos anos, perguntou ele,

de Rui Pina Coelho, enc. Gonçalo Amorim, Teatro Experimental do

Porto (Luis Araújo, Raquel Castro Joana de Verona e Carlos Marques), fot. José Martins.

Do alto da ponte, de Arthur Miller, enc. Gonçalo Amorim, Teatro Experimental do

Porto, 2011

(Jorge Mota

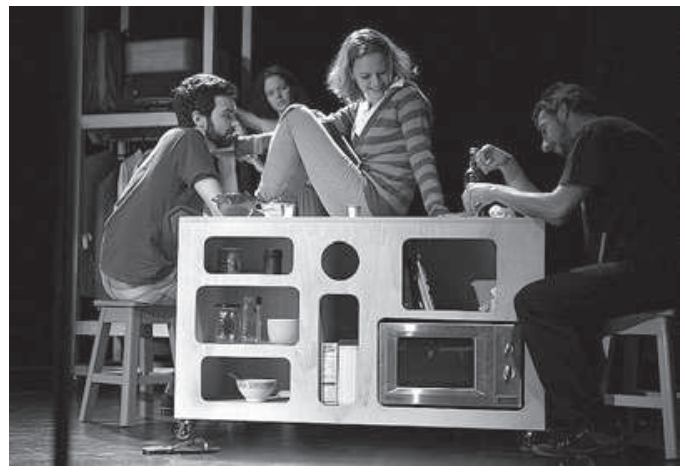

0 júri do Prémio da Crítica declarava na sua nota para a imprensa que a Menção Especial que atribuía a Gonçalo Amorim se referia ao trabalho de encenação que realizara em 2011. E percorrendo o seu gesto criativo em espectáculos como 0 jogador (a partir de Dostoievski), Do alto da ponte (sobre peça de Arthur Miller) e Já passaram quantos anos, perguntou ele (a partir do texto de Rui Pina Coelho),

reconhecemos, de facto, a confirmação de uma assinalável capacidade de criar mundos cénicos aliciantes, habitados por um ritmo vivo e integrando um jogo interpretativo de elevada qualidade e grande acerto.

Não descurando o aspecto plástico da cena - com a colaboração, nos três casos, da cenógrafa Rita Abreu - e pensando a movimentação cénica numa equilibrada relação entre o jogo em palco e o diálogo com a plateia, Gonçalo Amorim visou, sobretudo, uma forma de interpelação da dramaturgia no sentido de nela perceber as tensões que a habitam e de as tornar mais vivas e efectivas em palco.

0 espectáculo 0 jogador - sobre o romance de Dostoievski, adaptado por Emília Costa - numa produção do São Luiz Teatro Municipal, apresentou-se com uma dramaturgia algo complexa - pela dificuldade de dar a ver

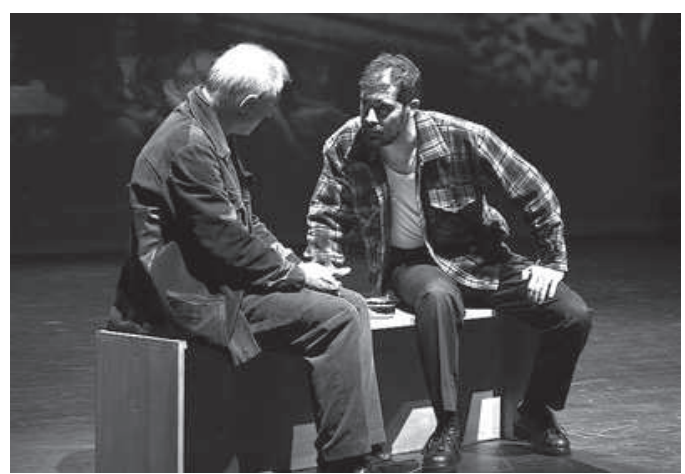

em palco a teia labiríntica das emoções desencontradas -, mas não deixou de ser uma construção cénica de grande expressividade. E essa expressividade, sendo claramente devedora da imaginação cenográfica de Rita Abreu, foi também mobilizada numa encenação feita de transbordamentos que, ao palco fixo, acrescentavam vectores irradiantes na localização da cena - em estruturas colocadas em altura, recuando até ao fundo do palco ou avançando pela sala e camarote - ao mesmo tempo que, no trabalho dos actores, imprimia, por vezes, traços de um dramatismo pungente.

Com Do alto da ponte, Gonçalo Amorim reencenava o universo de Miller que tinha já visitado na sua excelente criação de A morte de um caixeiro-viajante em 2010, numa produção do Teatro Experimental do Porto. Esta segunda visitação a Arthur Miller, co-produzida pelo TEP e pelo Teatro da Trindade / Inatel, teve estreia no Porto e apresentação posterior no Teatro da Trindade em Lisboa, e nela o encenador mais uma vez trabalhava num palco à italiana, sem que isso o impedisse de nele definir zonas de jogo diferenciado, num projecto que reunia preceitos brechtianos ao núcleo trágico que é central na peça de 

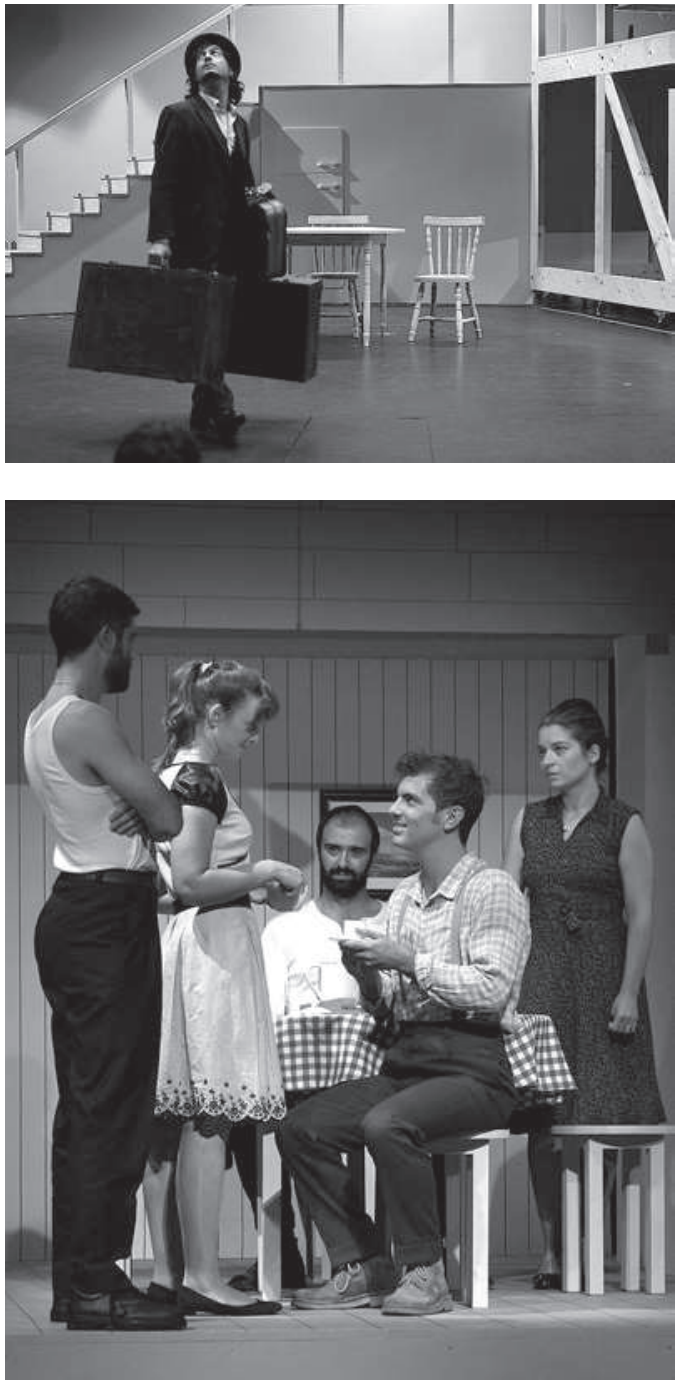

Miller. Assim, atrás do telão translúcido, ao fundo do palco, surgiam as figuras imóveis dos actores - quando não eram convocados em cena -, sobrepondo, nessa figuração, quer a ideia de bastidores para os intérpretes, quer um possivel coro destituído de voz, quer ainda a presença de espectadores imóveis que podiam ser imagem especular do auditório. No proscénio destacava-se a figura do advogado Alfieri em recorte próximo do narrador brechtiano. Na zona central do palco erguiam-se apontamentos cenográficos em recorte minimalista (mas de traçado realista) para a casa dos Carbone e a cabine telefónica que marcará a delação de Eddie. E o telão permitia também a projecção de imagens que tanto serviam a contextualização na zona portuária de Nova lorque, como apontamentos relativos aos mais recentes conflitos sociais na Grã-Bretanha.

Esse gosto de referir mundos ficcionais à realidade de hoje, que os mais jovens vivem tumultuosamente, reapareceu, de forma mais exasperada em Já passaram quantos anos, perguntou ele, sobre texto de Rui Pina Coelho. Interpelando a peça mítica de John Osborne, Look Back in Anger, de 1956, Rui Pina Coelho reposiciona as personagens num mundo mais próximo de nós, "numa mão um diploma, noutra, um passaporte", vivendo triangulações que se imaginam apaixonadas, ao ritmo de uma música frenética que procura traduzir essa vivência em permanente plano inclinado. Com uma criativa construção cenográfica de Rita Abreu e uma vibrante sonoplastia de Eduardo Brandão, Gonçalo Amorim criou um jogo cénico de uma vivacidade impulsiva em que à música - de ritmo e intensidade obsessivas - se aliava uma movimentação e lógica sequencial das cenas que, caleidoscopicamente, reenviavam para a caracterização que Jean-Pierre Sarrazac nos dá da dramaturgia contemporânea claramente reportada à "intensa rapsodização das escritas teatrais":

[...] escolha da irregularidade; caleidoscópio dos modos dramático, épico e lírico; reviravolta constante do alto e do baixo, do trágico e do cómico; junção de formas teatrais e extrateatrais, formando o mosaico de uma voz narradora e interrogante [...] (Sarrazac 2002: 229-230)

Em sintonia com o que afirma ser o seu credo estético - entre o abstraccionismo de Malevitch e o realismo de Cassavetes e Agnès Varda -, Gonçalo Amorim reafirmou nestes três espectáculos, que encenou em 2011, não apenas a sua capacidade de criar universos cénicos de grande plasticidade e rigor expressivo, mas também a razão de um projecto cénico que se organiza em torno de tensões que poderão habitar os textos com que trabalha, mas que ele sabe, com grande segurança, potenciar numa linguagem cénica muito própria.

\section{Referências bibliográficas}

AMORIM, Gonçalo (2008), "Agora, a necessidade do teatro", entrevista por Rui Pina Coelho, Sinais de cena, N. 12, Dezembro, APCT/CET, pp. 65-75. SARRAZAC, Jean-Pierre (2002), 0 futuro do drama, trad. de Alexandra Moreira da Silva, Porto, Campo das Letras.

\section{$<$}

$\mathrm{v}$

A morte de um caixeiro

viajante,

de Arthur Miller,

enc. Gonçalo Amorim,

Teatro Experimental do

Porto, 2010

(< Cláudio da Silva

v João Miguel Mota,

Maria João Pinho,

Cláudio da Silva,

Nuno Martins

e Inês Pereira),

fot. José Martins. 